\title{
Cloud Computing as an Alternative for on-Premise Software for Mauritian Hotels
}

\author{
Suman Ramkhelawan, Zarine Cadersaib, and Baby Gobin
}

\begin{abstract}
The hospitality industry is a flourishing backbone of the Mauritian economy and one of its pillars is the technological arm. Hospitality IT needs to adapt quickly to address and meet new challenges, increase operational flexibility and enhance overall guest experience while optimising costs on all fronts. The purpose of this study is to give a detailed analysis of the current IT infrastructure of hotels in Mauritius and to identify the major issues and challenges faced by the organisations in its management. The analysis has been carried out on premise and different stakeholders such as the functional managers, the IT support officers and end users have been interviewed for their appreciation of the actual IT infrastructure. Based on the issues and challenges faced by the different departments in their daily work routine, Cloud computing has been proposed as a viable solution to counter the challenges faced by the organizations in the management of their IT infrastructure. In this paper, the cost impact for one hotel for moving to the cloud SaaS model has been analysed. This work will extend on future works where the cost factor for different hotel categories and cloud models will be analysed.
\end{abstract}

Index Terms-Cloud computing, IT infrastructure, SaaS, hotels, CAPEX, OPEX.

\section{INTRODUCTION}

There are approximately 120 hotels in Mauritius ranging from 3 to 5 stars, with a total of over 12300 rooms and approximately 25000 bed places [1]. Their key business process include 1) making reservation for guests, 2) confirming thes reservations, 3 ) providing quality service, 4 ) sourcing quality food and beverages, among others. They also work in close collaboration with other stakeholders like suppliers and travel agencies. The long term strategy of most hotels is to increase their share on the international market, and be amongst the best service providers in the industry.

Up to now, no study has been carried out in the Mauritian hospitality industry, specifically with regards to the IT infrastructure in place. Therefore the basis of the actual study will be to analyze how Mauritian hotels organize their IT infrastructure ecosystem so as to maintain effectiveness, performance, availability and business continuity. The study will also focus towards recognizing the challenges and threats faced by hotels in managing their actual IT Infrastructure Park, and possible solutions to overcome those challenges.

For the present study, primary data as well as secondary data has been used. Primary Data has been collected through questionnaire, interviews, observation, and feedback, from

Manuscript received May 25, 2014; revised July 25, 2014.

The authors are with the University of Mauritius, Mauritius (e-mail: suman.ramkhelawan@umail.uom.ac.mu, z.cadersaib@uom.ac.mu, b.gobin@uom.ac.mu). hotel IT Managers, second line IT support staff, Trainers, HR managers, Line managers, and employees. Onsite observation has also been very useful to gather vital information. Secondary Data has been collected through analysis of statistical records, feedback forms, HR manuals, hotel policies and Standard of Procedures (SOPs), business magazines, and the internet.

\section{LITERATURE REVIEW}

\section{A. Cloud Computing}

Cloud computing, term coined in late of 2007, currently emerges as a hot topic due to its abilities to offer flexible dynamic IT infrastructures [2]. Cloud computing is a model for enabling ubiquitous, convenient, on-demand network access to a shared pool of configurable computing resources (e.g., networks, servers, storage, applications, and services) that can be rapidly provisioned and released with minimal management effort or service provider interaction [3]. This model of computing is touted to be a panacea for organizations which are resource hungry and at the same time limited in resources.

\section{B. Cloud Computing Architecture}

As can be seen in Fig. 1, Cloud computing architecture consists of 4 layers; the Hardware layer, the Infrastructure layer, the Platform layer and the Application layer [4].

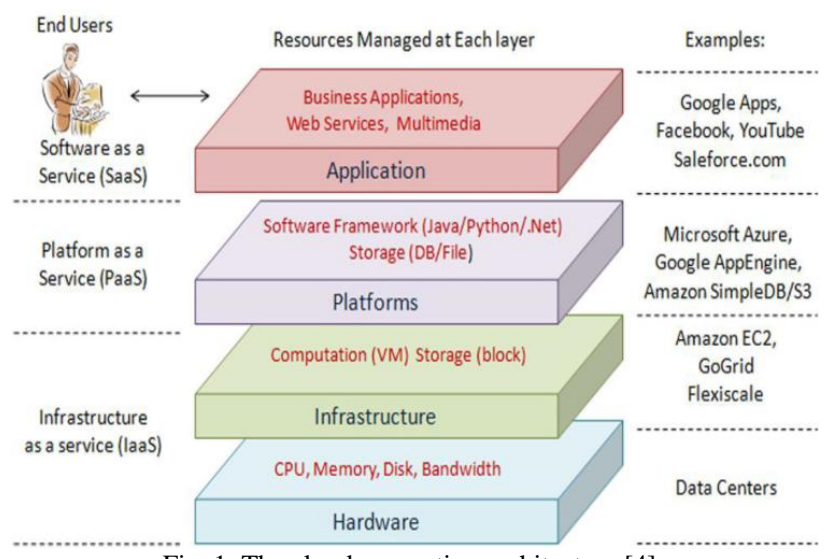

Fig. 1. The cloud computing architecture [4].

As compared to traditional computing architecture, the cloud computing architecture is more modular and thus allows each layer to evolve separately since each layer is loosely coupled with its adjacent layers.Cloud computing is normally delivered as three types of services which are: 1) Software as a Service (SaaS) [5], 2) Platform as a Service (PaaS) [6] and 3) Infrastructure as a Service (IaaS) [7]. Popular examples of SaaS are Hotmail, Google calendar and Salesforce.com. Two famous PaaS examples are Google App 
Engine and Force.com.Amazon Elastic Compute Cloud (EC2) and Amazon simple storage services (S3) are typical examples of IaaS solutions.

Cloud computing has four main deployment strategies. The first strategy is that of Private Clouds. In this setup the cloud services are delivered from a privately owned data center which is used solely by the organization that builds it and contains data for one organization only. Private clouds may deploy proprietary technologies inaccessible to other users of cloud services [7]. This deployment strategy is mostly used where the organization demands very specific infrastructures that are rarely used by other cloud users. Public clouds, which is the second type of clouds, is closest to the vision of utility computing that some have advanced since the 1960s [7]. Here the service providers can offer services to many different customers while hosting the data and applications in shared data centres. Public clouds have the advantage of being more attractive pricewise and provide different levels of quality of service. Intimately related to public clouds, multi-tenancy allows the same cloud application to be shared by different customers. A typical example is salesforce.com, which is one of the largest multi-tenant platforms. The third strategy is Community Clouds. In this constellation, the cloud infrastructure is dedicated to the needs of a community of organizations. They usually share the same interests in terms of policy and compliancy to standards, mission, and security requirements. It does not differ a lot from Private Cloud in terms of administration and hosting or ownership. The last deployment strategy is that of Hybrid Clouds. In this scenario the customers focus primarily on private clouds but rely on public clouds to provide the computing and storage needed to protect against unexpected or infrequent increases in demand for computing resources [8]. Hybrid clouds are particularly useful to provide load balancing, commonly termed as cloud bursting, during unanticipated peaks in demand.

\section{SURVEY OF IT INFRASTRUCTURE OF HOTELS}

\section{A. Survey Description}

For the purpose of this paper, a qualitative survey has been carried out in 25 hotels in Mauritius. Nine 5 Star, eight 4 Star, and eight 3 Star hotels were chosen for the survey so as to have a pool of heterogeneous properties to reflect real figures based on all market segments of the Mauritian hospitality industry. Among those 25 hotels, one Integrated Resort Scheme (IRS) property had also been included in the survey. IRS is a new concept where a guest can actually buy a villa and then put it back in the common pool of rental rooms so that other fortunate travellers can rent it as in a normal hotel. The revenue derived through this type of rental is then shared between the guest who owns the villa and the hotel.

The 25 hotels, including the IRS property, were assessed in terms of the IT infrastructure [9]. The design of the IT infrastructure is critical, since it will influence the overall quality of IT services provided. Since their embryonic stage all those 25 hotels surveyed have had hefty investments in servers, desktop computers and laptops to build their IT infrastructure. The structure has now morphed into complex multi-tiered client/server architecture with different levels of servers. The various components of the IT infrastructure of hotels assessedare as follows:

1) Computer hardware platforms. This refers to the types of servers, desktop PC and mobile devices used in hotels. These were assessed through the questionnaire so as to know the hardware used for the different systems housed at the hotel premises.

2) Operating systems platforms. The Operating Systems (OS) [10] were assessed so as to know the OS platform supporting the Property Management System (PMS), Point of Sales (POS), Procurement/Inventory Control software, Telephone Management System, File Server, and Accounting system used by the hotels.

3) Enterprise software applications. An assessment was made on ERP systems [11] to know if there is any ERP system in use at the properties, or individual systems were used for the different hotel functions/departments.

4) Networking/Telecommunications platforms. Currently most organizations have IT infrastructures spanned from several locations and connected in a specific way (topology) to support the business [12]. Networking and telecommunication actually constitutes the bulk of the capital expenditures for almost all hotels, and also serve as vital basis of all communication at the property. The need for it to be included in the questionnaire is because any migration to a more viable solution than on-premise will depend on the networking and telecommunication platforms.

5) Consulting and system integration services.Consultancy firm help manage the project, source pieces of the needed new technology, integrate these with existing systems, train users in advance of the system's introduction, and complete implementation according to schedule and budget [13].It has been included in the questionnaire as it will give an idea of the daunting task of integrating two or more systems together so that they exchange data, and to identify their cost implication.

6) Data management and storage. The questionnaire includes an assessment of database management systems (DBMS) [12] used by hotels to identify if common DBMS and common DB structures are used.

7) Internet based platforms. Being the corner stone of any organization going on the global market, the Internet [12] has somehow bolstered the hospitality industry worldwide and most particularly hotels in Mauritius. Indeed all the 25 surveyed hotels have stated having at least ten percent of reservations from online booking engines thanks to their Internet infrastructure. The internet may also open the door to other more viable options than on-premise management of IT resources.

\section{RESUlt OF THE SURVEY/DisCUSSION}

\section{A. Overview of the IT Infrastructure in Mauritian Hotels Based on Data Collected}

The main applications of the surveyed hotels in Mauritius are currently running on HP or Dell servers, which are on-premise and administered by the IT manager and/or IT officers. HP and Dell are also the premium brands preferred by hotels regarding the client PCs and laptops that act as clients for the end users. The 25 hotels surveyed have a 
homogeneous configuration since only Intel microchips equip their park of servers. For PCs and laptops, they use a mix of Intel and AMD processors. As far as Operating Systems are concerned, the hotels have followed the global trend by adopting the most utilized operating systems in the application servers and desktop computers sphere. Windows 2003 and Windows 2008 R2, with active directory, serve as domain controller and are also the operating systems running on almost all remaining servers. Amongthe 25 hotels in the survey, all have a Private automatic Branch Exchange (PaBX) serverfor telephone, and eight hotels have In-Room television through IP(IPTV). Both systems are supported exclusively by Linux OS. Regarding desktop computers and laptops, the entire park is powered by Windows XP professional edition, Windows 7, or Windows 8 OS. In 10 hotels, they are also using tablets on Android OS or iOS for departments like Guest Relations, Front Desk, and Sales and Marketing.

Out of the 25 Mauritian hotels surveyed, none use full-fledge ERP. The main reason given by hoteliers for not using ERP is that it is for more fit for manufacturing and engineering industries where you have production and supply chain businesses. They also mentioned that hotels will not be utilizing the whole range of facilities and functions of the ERP solution for a high price tag. The hotels have thus purchased individual software applications to automate each of their business functions for Accounting, Human Resource (HR), Procurement and Inventory Management, Property Management System (PMS), and Point of Sales (POS). Hoteliers therefore prefer to have individual applications installed on dedicated servers instead of having only one ERP system doing all the job of the different departments. If one application is unavailable due to issues, all other applications continue to run smoothly as they are on different databases, and ensure business continuity.

All the 25 surveyed hotels have adopted a centralized topology where all the data that is transmitted among nodes first travel to a central switch in the property.Two hotels have also partnered with world leaders, namely Alcatel Lucent, for implementing Gigabit Passive Optical Network (GPON). GPON can support the wide spectra of services such as: voice, Time Division Multiplex (TDM), Ethernet, Asynchrony Transport Mode (ATM), shared line, wireless extension on a single optical fibre core. The remaining 23 hotels are relying on Cisco or HP switches and routers to manage their network park, as illustrated in Fig. 2.

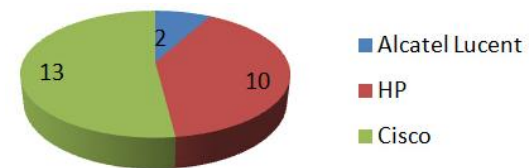

Fig. 2. Routers and switches used in hotel's network park.

Pertaining to the telephone system/ Private automatic Branch Exchange (PABX), 15 hotelshave opted for IP based Alcatel A4400, 2 hotels have opted for Cisco Nevotek telephone management system, 4 hotels have gone for Bosch $\mathrm{PaBX}$, and the remaining9 hotels are equipped with Nortel Meridian PaBX to handle the telephony system, as illustrated in Fig. 3. Linux and Windows 2003/2008R2 are also the common network operating system used for these PaBX systems.

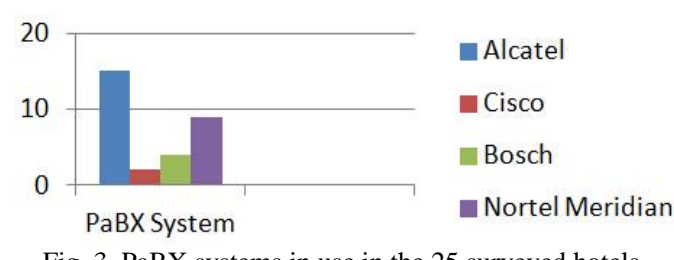

Fig. 3. PaBX systems in use in the 25 surveyed hotels.

In choosing capable consultants for the implementation of their IT infrastructure, all 25 hotels have chosen the safe way to deploy their hardware and software. The consulting firms act as bridge between the hotel and all the other vendors of other systems. The hotel in-house IT department would not necessarily have the necessary skills and expertise to successfully piece together all the components of the IT infrastructure. Interfacing all individual software applications also warrants special expertise that can only be delivered by consulting and system integration firms. Those hotels also have a legally-binding software maintenance agreement so that they get required support as and when needed.By so doing, hoteliers have minimized the risk of jeopardizing the whole effort in the project.

From the survey conducted in those 25 hotels, it has been found that most of the products used by the hotels are running on an individual Oracle $10 \mathrm{~g} / 11 \mathrm{~g}$ database, and in rare cases Microsoft SQL Server is used. This homogeneity of DBMSs has permitted most hotels to realize economies of scales in term of licensing. As for storage, the hotels are banking on a modular storage area network array (MSA) for their property management system (PMS) data. In most hotels, the MSA has fault tolerant and hot swappable hard disks meaning that any failed disks can be replaced without switching off the server. The remaining HP or Dell servers each have hard disks configured in RAID $1+0$ which provide a degree of fault tolerance. Furthermore, 23 of the surveyed hotels have a daily tape backup of all the individual oracle and SQL server databases. The tapes are kept away from the server rooms but still in hotel premises. Added to that, those 23 hotels also have third party software for backup, like Symantec Backup Exec, HP Data Protector, Oracle RMAN, and in some cases Oracle Dataguard (only five hotels have migrated to this new solution from Oracle).Two hotels do not have a reliable backup system even if they are aware of its consequences on business continuity, data security and integrity.

All the hotels have stated having at least ten percent of reservations from online booking engines thanks to their Internet infrastructure. The hotels use powerful Cisco, Alcatel, or HP routers and they all have at least a 2 megabyte fibre connection (4 megabyte line for 17 four star and five star hotels) to their Internet service provider (ISP). This allows the organizations to have a comfortable bandwidth for their Internet services such as email, web browsing, video conferencing and voice over IP (VoIP) using Skype. As regards to the hosting of their web site, 20 of those hotels have outsourced to hosting companies, and the remaining 5 are managing it themselves. They use Microsoft IIS and NET to run their web server. The same hosting companies also have the responsibility for the domain name registration (DNS) of those 20 hotels.Out of the 25 hotels, 20 hotels also have an in house FTP server which is mainly used by the off shore sales offices for the transfer of large and confidential documents over the Internet. 
The actual topology of the IT Infrastructure in $80 \%$ of the surveyed Mauritian hotels can be depicted as below in Fig. 4.

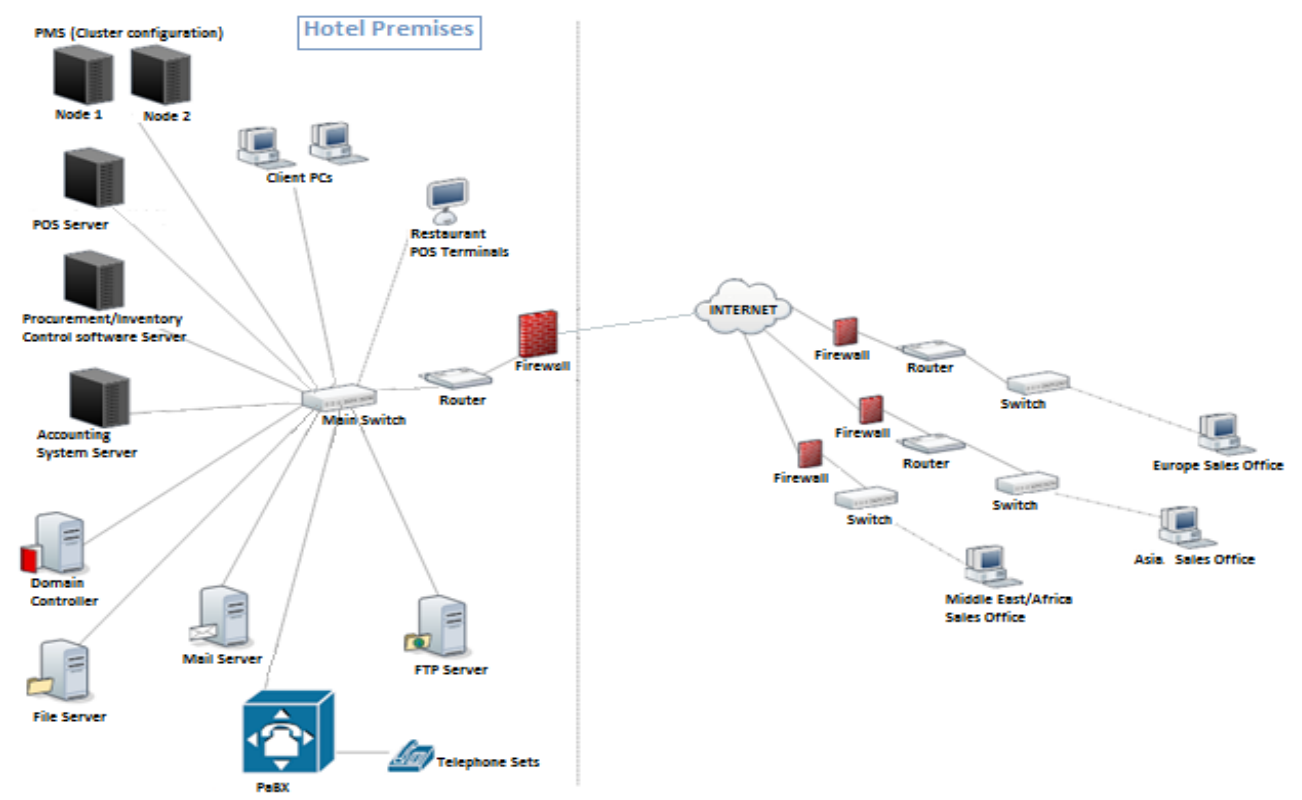

Fig. 4. IT Infrastructure in $80 \%$ hotels surveyed.

\section{B. Issues and Challenges with Managing the IT Infrastructure}

From the survey, it has been seen the main challenge faced by hotels is the recurrent high capital expenses (CAPEX) made in the IT infrastructure each time platforms such as computer hardware and operating systems inter alia reach their life time, and need upgrade or complete change. This affects the hotel's cash flow in the long run. This also entails the IT staff, which needs to be hired by the hotel for monitoring all those hardware and software to ensure business continuity. With one to three persons in the IT department of the hotels surveyed, it is challenging to maintain so many servers and PCs when the granularity of the task is considered. The database keeps growing in size and the local IT department has to ensure that the storage capacity remains scalable on the servers. Many hotels do not have a reliable backup and disaster recovery strategy since their backup tapes are kept on site. This represents a serious loop hole in terms of data availability in case of catastrophe such as fire. Complete data such as sales figures are not available to the different sales offices across Africa, Europe, and Middle-East in a timely manner. This can hinder the decision making process in those properties.

\section{Cloud Computing as a SOlution}

An obvious possible solution for Mauritian hotels would be cloud computing. In other words, if the benefits that hotels in Mauritius can reap from cloud computing are more than the risks and challenges that accompany cloud adoption, then it can be considered as feasible to migrate to cloud.

\section{A. Benefits of Cloud Computing}

In the case of hotels, any cloud pundit would agree that the most attractive benefit would be the conversion of capital expenses (CAPEX) into operating expenses (OPEX). Organizations not using clouds incur massive upfront investments in hardware and software when they start.
Furthermore the hardware infrastructure has to be changed or upgraded when it reaches its life time after three to four years and software has to be updated regularly to cater for new standards and technologies. In the case of SaaS, apart from the internet connectivity fee, the cloud adopters would pay only a license fee for software utilization over the web. Both fees are operational expenses which will enable the organization to have a better cash flow. Related to the economic benefits, cloud computing also provides a measured service whereby cloud systems automatically control and optimize resource by leveraging a metering capability [8]. This means that if Mauritian hotels adopt cloud computing, they will pay only for what they consume from the cloud and the usage is monitored and reported in a transparent way to all parties involved.

Buying growing computing power as and when they are needed is another advantage that Mauritian hotels can benefit from cloud computing. The capabilities and services from the cloud can be rapidly and elastically provisioned, in some cases automatically, to quickly scale out, and rapidly released to quickly scale in [3]. This means that hotels do not have to cater for growing computing power during high occupancy season since this can be purchased on the fly. Conversely, in a non-cloud environment,hotels would have expensive servers sitting almost idle during low occupancy seasons.

By reducing the need for corporate management to devote time and energy to overseeing the company's IT resources, cloud computing makes sure management's focus is on more prioritized matters [7]. Not having to spend considerable time on the management of the IT infrastructures will enable hoteliers to be more productive by focusing on their core business which is the delivering of high quality services to their guests.

\section{B. Cloud Computing Solutions That Would Be Applicable to Mauritian Hotels}

Cloud can be an interesting option for Mauritian hotels. Before elaborating on a possible cloud model, services that are available on cloud are described. 
1) PropertyManagement System (PMS). There are many PMS providers who are already proposing cloud solutions. This solution is actually totally new for Mauritian hotels as none of them have migrated to the cloud yet. Cloud PMS are being used by major hotel groups such as Starwood, Accor and Intercontinental in other parts of the world, like Europe, US and North America, and Asia Pacific region.Examples of Cloud PMS are Fidelio and Opera WebSuitefrom Micros Systems Inc., Webrezpro, and HTI's Nova PMS.

2) Point of Sales (POS). Some POS providers propose cloud based POS solutions that also have business intelligence facilities that can be accessed from the web by all the different departments such as the sales offices. Examples of Cloud POS are MyMicros.net from Micros Systems Inc., LivePOS, and my-axis-point POS.

3) Procurement/Inventory Management System. Cloud based inventory management software can be accessed from the web and used to perform tasks associated with ordering, receiving and conducting inventory counts, by store, enterprise, vendor, and item, manage Purchase order and daily receipt summary. Examples of cloud based inventory systems are: MyInventory.net from Micros Systems Inc., UniTender systems, and Procurify.

4) Email system. Email is a vital communication tool for any organization, but it also entails license fees for each terminal having the email client. GMAIL, Google's free email service available from the web and can replace the expensive Microsoft exchange server currently being used by most hotels in Mauritius. Many international organizations have migrated to this free web mail service.

5) File server. The file server is used to store and access large volume of information for the various hotel departments in their daily routine work. The IaaS models of Amazon S3and Microsoft Windows Azureprovide a secure and scalable solution to store and retrieve large amount of data from anywhere on the web. These cloud solutions can replace the on-premise file server that hotels have on their CAPEX.

6) Sales and marketing. A Customer Relationship Management system(CRM) and sales system is used to facilitate the daily tasks of the sales and marketing department in promoting and selling the destination. The SaaS model of Sales cloud from salesforce.com, Microsoft's Dynamic CRM, and Oracle CRM provide a convenient way to a have centralized sales figures from the web. Sales cloud features that can apply to Mauritian hotels are accounts and contacts management, marketing, leads and quote generation.

7) Backup and disaster recovery solution. Backup and recovery systems are of utmost importance forMauritian hotels to ensure business continuity in case of catastrophe on their premises. This is also an important stepping stone in attainingtheir strategic goals. The IaaS models of Amazon S3 and Microsoft Windows Azurecan be used as backup and disaster recovery solution. Having critical data mirrored off site using Amazon S3 will help achieve this objective at a minimal cost. Software escrow should be requested from cloud service providers. This will give hoteliers the guarantee that their data will always be available regardless of whether the cloud service provider survive or not. Software escrow is the provision of the source code by the owner or licensor on the source code to neutral third party(escrow agent) for safekeeping for the benefit of a licensee [14].

8) Computer hardware. Having onsite resources like servers and network systems to manage the different in-house systems is costly as it needs continuous maintenance and renewal of hardware at regular intervals so as to maintain competitive advantage in the market. It also means having experts to handle these systems on site. Amazon Elastic Compute Cloud(EC2) provides a cloud computing service by renting out computational resources to customers [15]. Customers can connect to the Internet and have access to virtual servers using their web browsers. This is suitable to avoid buying expensive servers.

\section{Costs for on-Premise Solution and SaaS Model}

Most of the hotels in the survey have at least a 2 megabyte fibre connection (4 megabyte line for 17 four star and five star hotels) to their Internet service provider (ISP), and this is sufficient for running applications from the cloud. However a backup connection should be readily available in case of major outages. Once their major applications are moved to the cloud, hotels will have the software subscription fees for software usage as operating costs. The only capital expenditure would be the purchase of thin clients to access the cloud application.

Table I below shows the costing for an on-premise solution for a 5 Star hotel with 220 rooms, based on mean figures for the different services from the internet. It is to be noted that PMS and POS licensing for both on-premise and cloud is based on the number of rooms at the property. The Procurement/Inventory system licensing cost is based on the number of stores at the hotel, and this in turn depends on whether it is a big hotel or not (this depends in turn on the number of rooms). The File Server, Accounting System, and HR software have a more or less fixed price as they do not depend on the number of rooms at the property.

TABLE I: COSTING OF ON-PREMISE SOLUTIONS

\begin{tabular}{|l|c|c|}
\hline Product & $\begin{array}{c}\text { Total } \\
\text { CAPEX-EURO }\end{array}$ & $\begin{array}{c}\text { Total OPEX- } \\
\text { EURO/Year }\end{array}$ \\
\hline PMS & $\mathbf{4 6 , 3 7 5}$ & $\mathbf{1 5 , 0 0 0}$ \\
\hline POS & $\mathbf{6 5 , 6 2 5}$ & $\mathbf{1 6 , 5 0 0}$ \\
\hline $\begin{array}{l}\text { Procurement/Inventory } \\
\text { Management System }\end{array}$ & $\mathbf{3 0 , 5 0 0}$ & $\mathbf{7 , 0 0 0}$ \\
\hline HR software & $\mathbf{2 9 , 0 0 0}$ & $\mathbf{2 , 0 0 0}$ \\
\hline Accounting Software & $\mathbf{3 2 , 0 0 0}$ & $\mathbf{3 , 0 0 0}$ \\
\hline File Server & $\mathbf{1 0 , 0 0 0}$ & $\mathbf{9 0 0}$ \\
\hline Total & $\mathbf{2 1 3 , 5 0 0}$ & $\mathbf{4 4 , 4 0 0}$ \\
\hline
\end{tabular}

Total cost of ownership $=\underline{257,900 \text { EURO }}$

Table II which follows shows the costing for a SaaS cloud model of the same 5 Star hotel with 220 rooms.

The PMS and POS licensing fees per room for cloud solution is minimal as compared to on-premise solution. For all other systems also the fees is minimal when compared with on-premise. The Capital Expenditure (CAPEX) is also minimal and it is converted as Operating Expenses (OPEX). The CAPEX decreases drastically by a margin of $80 \%$ and OPEX decreases by $44 \%$. The total cost of ownership in 
above tables shows that the latter is reduced by more than $70 \%$ when migrating to cloud.

To have a better overview of cost for different hotels and different cloud models, costs of each cloud Model (SaaS, $\mathrm{PaaS}$ and IaaS) per hotel category need to be computed.

TABLE II: COSTING OF SAAS CLOUD MODEL

\begin{tabular}{|l|c|c|}
\hline Product & $\begin{array}{l}\text { Total CAPEX - } \\
\text { EURO }\end{array}$ & $\begin{array}{l}\text { Total OPEX } \\
\text { EURO/Year }\end{array}$ \\
\hline PMS & NIL & $\mathbf{1 4 , 0 0 0}$ \\
\hline POS & NIL & $\mathbf{1 1 , 0 0 0}$ \\
\hline $\begin{array}{l}\text { Procurement/Inventory } \\
\text { Management System }\end{array}$ & NIL & $\mathbf{3 , 0 0 0}$ \\
\hline $\begin{array}{l}\text { HR software (hosted on } \\
\text { Amazon EC2) }\end{array}$ & $\mathbf{1 9 , 0 0 0}$ & $\mathbf{7 0 0}$ \\
\hline $\begin{array}{l}\text { Accounting Software (hosted } \\
\text { on Amazon EC2) }\end{array}$ & $\mathbf{2 2 , 0 0 0}$ & $\mathbf{7 0 0}$ \\
\hline $\begin{array}{l}\text { File server hosted on Amazon } \\
\text { S3) }\end{array}$ & NIL & $\mathbf{2 0 0}$ \\
\hline Total & $\mathbf{4 1 , 0 0 0}$ & $\mathbf{2 9 , 6 0 0}$ \\
\hline
\end{tabular}

Total cost of ownership $=\underline{70,600 \text { EURO }}$

\section{DISCUSSION}

The risks and challenges that hotels may face in the process of adopting cloud computing can be grouped into five key areas:

\section{A. Security and Privacy}

Information security and privacy is one of the most important challenges for hoteliers to ensure that the hotel cloud and the sensitive data that it accommodates are safe from cyber attacks.Isolation failureis the risk of failure of mechanisms separating storage, memory and routing among different tenants in case the hotels use a public or a community cloud [16].

\section{B. Outsourcing Risks}

Portability of data and vendor lock-in is another risk whereby hotels may depend on a cloud vendor for services, unable to use another cloud vendor without significant switching costs. Control and ownership of data may arise with the migration of hotel's data to the Cloud. This is really critical for hotels as it concerns their vital data and confidential figures.

\section{Availability and Performance}

Could computing's dependence on internet connection is another major challenge as the Internet is not considered as a trusted network. Service availability and possible outages depends a lot on reliability of the cloud vendor. So, hotels should choose their cloud provider with due diligence and take into consideration their business continuity.

\section{Standards and Legal Issues}

Since cloud computing is relatively new in Mauritius, standards and laws are still being developed.

\section{E. Change Management and Organizational Issues}

Financial risk is another major challenge where there's always the possibility that cloud adoption might fail to deliver expected benefits. Hotels should be informed for the current state of systems and technologies that are used in different hotels in other areas of the world before adopting cloud computing, a task that can be quite demanding.Legacy systems and their integration with Cloud may be difficult due to lack of interoperability among technologies used.

\section{CONCLUSION}

It can be concluded that the issues and challenges, related to IT infrastructure management, faced by the 25 hotels surveyed are mainly related to high CAPEX, complexity of maintenance and finally availability of reliable figures in a real time fashion. Different models of cloud computing have been recommended to recoup part of the CAPEX. Furthermore cloud computing also provides the organization with a convenient way to have reliable information for sound decision making and by the same token allows management to concentrate on one of its core objectives which is to give outstanding services to its guests. However hotels should be careful and address the challenges and risks of cloud computing before adopting any cloud service or deployment strategy.

\section{ACKNOWLEDGMENT}

We are thankful to all the Mauritian hotels and their staff who have provided us with valuable information on their IT Infrastructure.

\section{REFERENCES}

[1] Statistics Mauritius. (2013). International Travel and Tourism. [Online]. $12-14 . \quad$ pp. Available: http://statsmauritius.gov.mu/English/Publications/Pages/Publication-P rogramme.aspx.

[2] L.Wang, G. Laszewski, A. Young, M. X. H. Kunze, T. Jie, and F. Cheng, "Cloud computing: Aperspective study," New Generation Computing, vol. 28, no. 2, pp. 137-146, 2010.

[3] P. Mell and T. Grance, "The NIST definition of cloud computing (Draft)," National Institute of Standards and Technology, pp. 1-3, 2011.

[4] Q. Zhang, L. Cheng, and R. Boutaba, "Cloud computing: State-of-the-art and research challenges," The Brazilian Computer Society, 2010.

[5] C. S. Yoo, "Cloud computing: Architectural and policy implications," Review of Industrial Organization, vol. 38, no. 4, p. 408, 2010.

[6] C. S. Yoo, "Cloud computing: Architectural and policy implications," Review of Industrial Organization, vol. 38, no. 4, pp. 405-421, 2010.

[7] J. A. Bowen, "Cloud computing: Issues in data privacy/security and commercial considerations," Computer \& Internet Lawyer, vol. 28, no. 8, Hoboken, New Jersey: John Wiley \& Sons, Inc., pp. 1-8, 2011.

[8] C. S. Yoo, "Cloud computing: Architectural and policy implications," Review of Industrial Organization, vol. 38, no. 4, p. 409, 2010.

[9] K. C. Laudon and J. P. Laudon, Management Information Systems: Managing the Digital Firm, 13th Ed, USA: Pearson Prentice-Hall, 2011.

[10] S. Liu, "A practical framework for discussing IT infrastructure," IT Professional, vol. 4, no. 4, pp. 14-21, 2002.

[11] C. Berchet and G. Habchi, "The implementation and deployment of an ERP system: An industrial case study," Computers in Industry, vol. 56, no. 6, pp. 588-605, 2005

[12] L. F. da Silva and F. B. e Abreu, "Reengineering IT infrastructure: A method for topology discovery," Quality of Information and Communication Technology Seventh International Conference, pp. 331-336, 2010.

[13] E. B. Swanson, "Consultancies and capabilities in innovating with IT," Journal of Strategic Information Systems,vol. 19, no. 1, pp. 17-27, 2010.

[14] J. A. Bowen, "Cloud computing: Issues in data privacy/security and commercial considerations," Computer \& Internet Lawyer, vol. 28, no. 8, p. 7, 2011.

[15] S. Chaisiri, R. Kaewpuang, L. Bu-Sung, and D. Niyato, "Cost minimization for provisioning virtual servers in Amazon elastic compute cloud," in Proc. 19th International Symposium on Modeling, Analysis \& Simulation of Computer and Telecommunication Systems (MASCOTS), 2011, pp. 85-95. 
[16] FORBES. http://www.forbes.com/fdc/welcome_mjx.shtml.

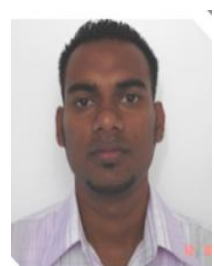

Suman Ramkhelawan completed the professional graduate diploma in IT from the British Computer Society (BCS) in 2006, and is completing his MSc in software engineering projects and management at the University of Mauritius.

$\mathrm{He}$ is currently working as PMS and IFC implementation specialist at Micros Fidelio (Mauritius) Ltd, a subsidiary of Micros Systems Inc. Mr. Ramkhelawan is a member of the British Computer Society (BCS).

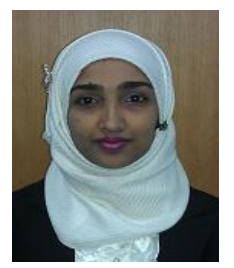

Zarine Cadersaib was born in Mauritius. She has a $\mathrm{BEng}$ (Hons) in computer science and engineering from the University of Mauritius awarded in 2002.

She worked as a senior programmer and an analyst programmer at DCDMC/Accenture Mauritius Ltd from 2002-2006 before joining the University of Mauritius as a lecturer in 2006 (till date). Her research interests include context aware applications, enterprise systems, EAI and cloud computing. She has publications in conference proceedings, journal articles and research bulletin and she also designed a distance learning manual on Management Information systems for the University of Mauritius in 2009.

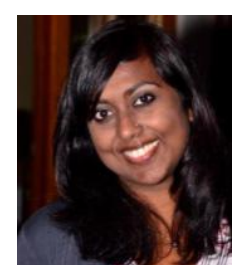

Baby A. Gobin is a lecturer in the Department of Computer Science and Engineering at the University of Mauritius since 2009. She has a BSc.(Hons) in computer science and engineering, an MSc. in ebusiness and is completing her $\mathrm{PhD}$ in computer science. Her research thesis discusses on a new and agile approach to develop ontology modules.

She is also the founder and chairperson of the ITS Research and Consultancy Group which has as aim to investigate and promote the use of IT in the Mauritius. The group is currently working on two projects. The first one is the implementation of Information Systems at the National Empowerment Foundation, a body working for the empowerment of households, which are under the threshold of poverty. The second project is a study on technology acceptance among small and medium enterprises. This project is being done in collaborating with the SMEDA, a para-statal body set up by the government of Mauritius to help SMEs. 